\title{
A atenção no teatro contemporâneo: um estudo crítico dos escritos de Lehmann, Desgranges e
}

\section{Rancière $^{1}$}

\section{Leonel Martins Carneiro}

Universidade de São Paulo / Doutorando

Teoria e Prática do Teatro / Sílvia Fernandes da Silva Telesi

FAPESP

Ator, diretor, produtor e professor

Este artigo apresenta um recorte da pesquisa de mestrado intitulada "A atenção e a cena", desenvolvida junto ao PPGAC-USP entre 2009 e 2011. Busca-se, a partir do conceito de atenção, desenvolvido por Hugo Munsterberg (2004), realizar um estudo crítico de obras de três autores, cujas teorias exerceram muita influência no Brasil neste início do século XXI. Com a análise de como o tema da atenção transpassa os estudos de Lehmann (2007), Desgranges (2009) e Rancière (2010), espera-se abrir novas possibilidades de discussão teórica da cena contemporânea.

Palavras-chave: atenção, ator, espectador, experiência, século XXI .

Title: The attention in the contemporary theater: a critical study of Lehmann, Desgranges and Rancière

Abstract: This article presents part of the Master thesis titled "A atenção e a cena", developed between 2009 and 2011 at the University of São Paulo. For this reflection was used the subject of attention, developed by Hugo Munsterberg (2004), was chose some of the theatrical theories produced in the early twenty-first century to review. Three authors whose theories had exerted much influence in Brazil were elected to be studied. The analysis of subject of attention in the studies of Lehmann (2007), Desgranges (2009) and Rancière (2010), intends to open new possibilities for theoretical discussion about the contemporary theater.

Keywords: attention, actor, spectator, experience, twenty-first century.

Título: La atención en el teatro contemporáneo: un estudio crítico de los escritos de Lehmann, Desgranges y Rancière

Resumen: Este artículo presenta parte de la tesis de maestría titulada "A atenção e a cena", desarrollado entre 2009 y 2011 en la Universidade de São Paulo. Para esta reflexión se eligió el tema de la atención desarrollado por Hugo Munsterberg (2004) como una base para el estudio crítico de las obras de tres autores cuyas teorías ejercieron una gran influencia en Brasil a principios del siglo XXI. Con el análisis del tema de la atención en los estudios de Lehmann (2007), Desgranges (2009) y Rancière (2010), se espera que se abran nuevas posibilidades para la discusión teórica sobre la escena contemporánea.

Palabras-clave: atención, actor, experiencia, espectador, siglo XXI

Durante a pesquisa de mestrado procurou-se, sem sucesso, qualquer estudo sobre a atenção na cena contemporânea ${ }^{2}$. Apesar de não existir nenhum estudo que desenvolva uma reflexão específica e direta sobre o tema, percebe-se que a atenção aparece como um temática transversal em vários trabalhos que tem por objeto o teatro contemporâneo. Este artigo busca mapear o campo de pesquisa, fornecendo subsídios para próximos estudos. ${ }^{3}$ 
Antes de entrar efetivamente no campo das artes cênicas é necessário efetuar uma digressão no sentido de esclarecer que pesquisa da atenção pode ter diversos rumos. Aqui parte-se da linha de estudo que surge quando, em 1916, Hugo Munsterberg se utiliza de seus conhecimentos sobre o recém criado campo da psicologia para analisar o efeito do filme e do teatro sobre o espectador, focando em sua significação. Para Munsterberg (2004) a atenção é a primeira e a principal função da mente na significação do mundo para o ser humano, ou seja, tudo que existe em nossa consciência passa pela atenção.

A atenção que, para Munsterberg, no início do século XX, era necessária para a compreensão da história do drama, passa a partir da perspectiva do teatro contemporâneo a constituir-se como uma espécie de linguagem autônoma que pode ser vista em alguns dos espetáculos atuais. Partindo-se desta constatação busca-se, de maneira teórica, realizar um mapeamento de como a atenção aparece em alguns dos pensadores que refletem sobre a condição do espetáculo e do espectador contemporâneos. Para tal mapeamento elencaram-se algumas das reflexões mais influentes neste início de século em terras brasileiras. Para começar tal mapeamento parte-se de um artigo escrito por Hans-Ties Lehmann, autor de Teatro Pós-dramático:

[na cena contemporânea] uma poética da compreensão é substituída por uma poética da atenção que armazena o estímulo e o mantém na pré consciência; que lhe possibilita uma inscrição efêmera no aparelho perceptivo sem permitir que ele se dissipe num ato de compreensão: um rastro de memória ao invés de consciência, a compreensão fica adiada. (LEHMANN, 2007b, P.146)

O que Lehmann chama de "poética da atenção da cena contemporânea" pode ser compreendido a partir da análise dos efeitos que as teatralidades contemporâneas exercem sobre os espectadores. Tais teatralidades ${ }^{4}$ se constituem de signos instáveis, fluídos que se desfazem diante da tentativa de compreensão dramática e racional. É preciso entender que quando Lehmann fala sobre uma poética da atenção ele está se referindo a uma poética que age diretamente sobre a atenção do espectador, ou seja, a atenção tem seu status alterado passando de efeito de uma poética (como acontece no teatro dramático) para um elemento organizador de uma poética.

Para Lehmann (2007), diante da mudança na percepção do espectador, não resta alternativa senão promover uma mudança estrutural na práxis teatral. Ele nos conduz em sua obra pelo processo de desestruturação do texto teatral, das vanguardas históricas do início do século XX até o surgimento das peças paisagens de Gertrude Stein. Demonstra como fundamentais para o teatro contemporâneo as experiências expressionistas, que visavam afetar sensivelmente o espectador e a materialização de imagens oníricas do surrealismo. Por trás de toda esta mudança na percepção do espectador, que provoca uma revolução no campo das artes, está a questão da atenção. 
Ao analisar o emprego da focalização da atenção enquanto técnica teatral, o pensador alemão indica que o teatro pós-dramático libera o fator formal-ostensivo da cerimônia de sua mera função de intensificar a atenção e o faz valer por si mesmo como qualidade estética, longe de qualquer referência religiosa ou cultural. (2007, P 115) Portanto, o prazer deste teatro está ligado não ao seu mythos, como até então se fazia, mas a seu caráter objetivo e concreto das imagens, ou seja, a seu opsis e à capacidade de choque deste sobre nossa atenção.

Isso remete novamente à questão do papel da mimesis no teatro. Enquanto nos gêneros trágicos e dramáticos é permitido ao espectador identificar-se com a personagem, estabelecendo uma relação direta, a partir do aspecto mítico da peça, já no teatro pós-dramático, abordado por Lehmann, o elo mimético está vinculado às imagens que podem ser fruídas pela plateia na forma de livre associação, sem uma unidade de sentido pré-determinada. O espetáculo propõe ao seu público o prazer da solução do enigma.

\begin{abstract}
A mimese é por ele [Aristóteles] compreendida como uma espécie de mathesis: como um aprendizado que se torna prazeroso pelo deleite do reconhecimento do objeto da mimese um prazer que satisfaz apenas a multidão, mas que não é exigido pelo filósofo: "o aprendizado propicia maior prazer não só ao filósofo, mas igualmente aos demais homens. É por isso que eles se deleitam com a visão de imagens, pois ao contemplá-las aprendem algo e procuram deduzir o que é cada uma. (LEHMANN, 2007: 63-64)
\end{abstract}

Para abordar as alterações que a arte teatral sofreu entre o fim do século XX e início do XXI, deixando o campo da narrativa puramente dramática, para adentrar em territórios híbridos, adquirindo inclusive novas funções sociais e novas formas de tratar a atenção do espectador, surgem teorias que propõe-se a trilhar outros caminhos para o estudo da fruição do espectador. Diversas pesquisas como as de Flávio Desgranges (2009), Jacques Rancière (2010) - e do próprio Hans-Ties Lehmann- falam sobre a mudança do papel do espectador no teatro contemporâneo e de uma refuncionalização, não só da arte teatral, como também do olhar (e da atenção) do espectador diante dela.

A consequência de tudo isto [de novo que o teatro contemporâneo propõe] é uma mudança na atitude por parte do espectador. Na hermenêutica psicanalítica, fala-se de "atenção flutuante por igual". Freud elegeu este conceito para caracterizar a maneira como o analista escuta o analisado. Tudo depende aqui de não compreender imediatamente. Ao contrario, a percepção tem que permanecer aberta para esperar, em pontos inteiramente inesperados, ligações, correspondências e explicações que fazem o que se disse antes ser encarado sob uma luz muito diversa. Assim o significado permanece por princípio suspenso. Justamente aquilo que é secundário e insignificante é registrado com exatidão, porque em seu nãosignificado imediato pode se mostrar significativo para o discurso da pessoa analisada. De modo similar, o espectador do teatro pós-dramático não é impelido a uma imediata 
assimilação do instante, mas a um dilatório armazenamento das impressões sensíveis com “atenção flutuante por igual". ( LEHMANN, 2007, P. 145)

Há de se pensar até que ponto o espectador do teatro brasileiro adere ao tipo de assimilação que é proposto pelo teatro pós-dramático, do qual nos fala Lehmann, ou mesmo se é necessário algum tipo de formação do público para fruição deste teatro, tão distante da linguagem da telenovela ou mesmo do drama burguês do século XVIII ${ }^{5}$. Dentre os principais elementos técnicos para o ator lidar com a atenção no teatro pós-dramático, provocando choques e suspensões no espectador, pode-se destacar, conforme a proposta de Lehmann, a musicalização, a corporeidade, a presença, a criação de lacunas de significação, a não-atuação, exposição dos procedimentos e a eliminação da divisão entre palco e plateia. Todos estes elementos propiciam uma nova forma do espectador ver o teatro, numa relação mais tátil com a obra.

\begin{abstract}
No teatro pós-dramático o corpo "afeta" o espectador menos como informação do que como comunicação. Essa comunicação corresponde sobretudo ao modelo de um "contágio" pelo teatro, à maneira da metáfora de Artaud em "o teatro e a peste". A comunicação como contágio por uma bactéria não é a transmissão de informação; antes, equivale a uma fusão e uma participação miméticas. (LEHMANN, 2007, P. 338)
\end{abstract}

Uma descrição detalhada desta alteração da relação entre espectador e ator pode também ser vista no trabalho de Flávio Desgranges (2009), que se debruça sobre a questão da refuncionalização da arte teatral. Sua contribuição para nossos estudos se dá, principalmente, na apresentação das mudanças que o ato do espectador sofreu em decorrência das modificações nas condições em que vivemos atualmente, em um mundo com cada vez mais informação e velocidade e, na discussão dos impactos que isso gera na arte teatral.

Desgranges (2009, p.12) aponta que o ato artístico contemporâneo solicita uma disponibilidade distinta do espectador em comparação aquela que exige o espetáculo dramático. Tal disposição não pode ser compreendida como um talento natural, mas sim como uma conquista cultural. A ideia de recepção tátil, implementada por Flávio Desgranges a partir das ideias de Walter Benjamin, apresenta uma das possibilidades de fruição dos espetáculos contemporâneos. Segundo Desgranges, para se adaptar a este tipo de recepção os espectadores teriam de ser reeducados. Este modo receptivo que propõe Desgranges faz com que o objeto avance sobre o indivíduo tocando-lhe o íntimo e fazendo emergir uma série de conteúdos armazenados em sua memória. 
As alterações na percepção solicitam procedimentos artísticos modificados para provocar a irrupção da memória involuntária. Somente uma recepção distraída, em que o consciente seja surpreendido, pego desatento, poderia se deixar atingir pelo instante significativo em que, na relação com o objeto artístico, o olhar nos é retribuído, nos toca o íntimo, e faz surgir o inadvertido, trazendo à tona experiências cruciais do passado. $\mathrm{O}$ encontro com a arte se coloca, desde então, fundamentalmente vinculado com a proposição e a produção de experiências. (DESGRANGES, 2009, P.95)

A hipótese levantada por Flávio Desgranges corrobora com a suposição de que a chamada cena contemporânea é uma cena que se oferece ao espectador de modo semelhante ao trauma, segundo o que é descrito por Freud (2010), ou seja, usa do elemento surpresa e do choque como estratégias para potencializar a lembrança do acontecido e o caráter experiencial do momento vivido

A função social do teatro [contemporâneo] se manifesta em sua plenitude quando a experiência artística do espectador, em sua relação com a obra, se coloca em vias de colisão com as perspectivas estéticas e históricas que condicionam a sua percepção, pré-formando seu entendimento de mundo, retroagindo, assim, sobre seu comportamento, seu modo de sentir, pensar e agir na vida social. (DESGRANGES, 2009, p.23)

Diante disto, para que a experiência estética do espectador do teatro contemporâneo seja efetiva e socialmente funcional, é necessário que a atenção do espectador seja frustrada e despertada. É importante notar que os procedimentos de quebra, propostos pelo teatro épico, se tornaram habituais aos espectadores, não causando mais o estranhamento. Para continuar causando este estranhamento os espetáculos devem sempre reinventar estes procedimentos, vinculados às opções éticas, estéticas e políticas dos produtores. Muito dos esforços de encenadores do teatro contemporâneo, tais como Romeo Castellucci (Socìetas Raffaello Sanzio) e Antonio Araújo (Teatro da Vertigem) estão concentrados em uma produção de experiências capazes de surpreender a atenção do espectador, imprimindo-se em sua memória involuntária.

Outro exemplo de como a perspectiva dos estudos atencionais pode ser encontrada no pensamento sobre o teatro, está apresentada no artigo de Rancière (2010) sobre o espectador emancipado, no qual ele aborda, de modo muito instigante, a questão da refuncionalização do teatro.

O teatro deve ser trazido de volta à sua verdadeira essência, que é o contrário daquilo que é normalmente conhecido como teatro. O que se deve buscar é um teatro sem espectadores, um teatro onde os espectadores vão deixar esta condição, onde vão aprender coisas em vez de ser capturados por imagens, onde vão se tornar participantes ativos numa ação coletiva em vez de continuarem como observadores passivos. (RANCIÈRE, 2010, P.109)

Este teatro sem espectadores, remete ao teatro grego. Rancière não quer dizer que o espectador deve ser retirado da sala, mas que ele deve ser mais ativo e não depender do ator para 
formular sua ideia sobre o espetáculo. Esta concepção se aproxima da concepção brechtiana de um espectador da era científica. É como se as pessoas ali reunidas estivessem juntas num esforço de atribuir um sentido ao que se apresenta.

Em um segundo momento, o filósofo francês aponta que a visão clássica de teatro e de pedagogia estão intimamente relacionadas. Nelas está pressuposto que o mestre (ou o artista) deve sempre manter uma distância entre ele e o aluno/espectador. Essa distância deve existir para que o mestre esteja sempre na posição de ser mais sábio que o aluno, ou seja, para que esta relação nunca seja horizontal.

Por um lado, o espectador deve ser libertado da passividade do observador que fica fascinado pela aparência à sua frente e se identifica com as personagens no palco. Ele precisa ser confrontado com o espetáculo de algo estranho, que se dá como um enigma e demanda que ele investigue a razão deste estranhamento. Ele deve ser impelido a abandonar o papel de observador passivo e assumir o papel do cientista que observa fenômenos e procura suas causas. (RANCIÈRE, 2010, P.109)

O texto de Rancière aborda o teatro da atualidade fazendo uma espécie de exaltação da fruição por meio de uma "atenção épica". É como se ele tomasse para si a tese do teatro épico de Brecht e a atualizasse frente à sua percepção do mundo contemporâneo. Enquanto a linha seguida por Desgranges exalta o papel da distração na fruição da cena, Rancière ilumina a questão de uma atenção ativa. Pensa-se que estas são duas formas de fruição necessárias à cena contemporânea, que distrai seu espectador e surpreende-o, produzindo uma experiência que em seu processamento, muitas vezes tardio, acaba por gerar um aprendizado a partir da história individual de cada espectador.

Estes [espectadores] são observadores e intérpretes distantes daquilo que se apresenta
diante deles. Eles prestam atenção ao espetáculo na medida da sua distância. O dramaturgo
e o ator não querem "ensinar" nada. De fato, eles estão mais que cautelosos hoje em dia
quanto a usar o palco como um meio de ensino. Eles apenas querem proporcionar um
estado de atenção ou uma força de sentimento ou ação. Mas eles ainda supõem que aquilo
que vai ser sentido ou entendido será o que eles colocaram no próprio roteiro ou
performance. (RANCIÈRE, 2010, P.116)

Este trecho de seu artigo é fundamental para que se possa entender que Rancière, ao mesmo tempo que se refere à cena da atualidade, clama por uma nova cena, na qual os artistas assumam o risco da não condução do espectador a uma compreensão da obra. Ele pede um novo tipo de criação no qual este estado de atenção, que precede a uma atenção involuntária, não é o bastante. Ele pede um espetáculo que possa criar uma relação realmente dialética entre ator e espectador, no qual exista espaço para uma compreensão do que é completamente ignorado pelos criadores da obra. 
Um espectador que olha voluntariamente para algo e formula suas próprias ideias sobre aquilo que vê cria a possibilidade de surpreender o próprio criador com novos sentidos para aquela criação. O que propõe Rancière é que o artista possa, em um diálogo franco e aberto, também se colocar como um pesquisador, que reunido com os espectadores cria significados únicos e inesperados, de forma horizontal. Deste modo ele propõe que seja possível uma emancipação do espectador.

\begin{abstract}
A emancipação parte do princípio oposto [do que tem o teatro da atualidade], o princípio da igualdade. Ela começa quando dispensamos a oposição entre olhar e agir e entendemos que a distribuição do próprio visível faz parte da configuração de dominação e sujeição. Ela começa quando nos damos conta de que olhar também é uma ação que confirma ou modifica tal distribuição, e que "interpretar o mundo" já é uma forma de transformá-lo, de reconfigurá-lo. (RANCIÈRE, 2010, P.115)
\end{abstract}

A tese do filósofo é, acima de tudo, política. $\mathrm{O}$ espectador emancipado seria um espectador com o mesmo poder do criador, pois em seu ato de interpretar o mundo reconheceria o poder de barganha político e de transformação da realidade. Como isso poderia ser feito tecnicamente é algo a se pensar, mas Rancière propõe que:

\footnotetext{
Nós não precisamos transformar espectadores em atores. Nós precisamos é reconhecer que cada espectador já é um ator em sua própria história e que cada ator é, por sua vez, espectador do mesmo tipo de história. (RANCIÈRE, 2010, P.118)
}

Assim, Rancière, nesta proposição de uma relação dialética entre artista-espectador, retoma a perspectiva marxista histórico-cultural de uma forma renovada. Propondo uma nova significação social para o teatro, seguindo e extrapolando as linhas desenhadas por Brecht, Kracauer e Benjamin durante o século XX.

Nestes primeiros doze anos do século XXI o teatro foi abordado nas mais diversas perspectivas. Afigura-se, em sua maior parte das teorias propostas, bem como nas três teorias sobre as quais debruça-se este artigo, a importância da temática da atenção do espectador. Ainda que não seja um tópico abordado diretamente pelos autores como forma de um capítulo, por exemplo, propõe-se que a atenção é estruturante das teorias tratadas uma vez que quando fala-se do espectador a atenção é um ponto chave para entender como se processam os significados da cena. Por outro lado, quando fala-se dos espetáculos, percebe-se a importância que a atenção ganha, constituindo um tipo de linguagem que mais que visar a compreensão pelo espectador, procura manipular diretamente a sua atenção. 
Conclui-se, diante destas constatações, que o estudo da atenção, em suas possíveis relações com outros conceitos como a memória e a imaginação, conforme a proposta de Hugo Munsterberg, pode fornecer alternativas a teoria teatral para tratar do teatro contemporânea, tanto no que diz respeito a sua produção, quanto a sua recepção, ou ainda, pode-se vislumbrar a atenção como um ponto de interação entre estes dois campos de estudo. A atenção do ator está profundamente ligada a do espectador, bem como as expectativas do encenador e do dramaturgo de criação de sentidos. Ainda que esta seja uma primeira tentativa, a atenção parece possibilitar o encontro entre estas temáticas, há tanto distantes.

\section{Bibliografia}

AGAMBEN, Giorgio. O que é contemporâneo? - e outros ensaios. Chapecó: Argos, 2009.

ANDREW, J. Dudley. As Principais Teorias do Cinema. Rio de Janeiro: Jorge Zahar Editor, 1989.

BENJAMIN, Walter. O Narrador. In: Magia e técnica, arte e política: ensaios sobre literatura e história da cultura - V2. São Paulo: Brasiliense, 1985.

BRECHT, Bertolt. Teatro Dialético. Rio de Janeiro: Civilização Brasileira, 1967.

CARNEIRO, Leonel Martins. A atenção e a cena. Dissertação (mestrado). São Paulo: Universidade de São Paulo/Programa de Pós-Graduação em Artes Cênicas, 2011.

CRARY, Jonathan. A visão que se desprende: Manet e o observador atento no fim do século XIX. In CHARNEY, Leo; SCHWARTZ, Vanessa R. (Org.). O cinema e a invenção da vida moderna. São Paulo: Cosac \& Naify, 2001, p. 67-94.

Suspensions of perception: attention, spectacle, and modern culture. Massachusetts/London: MIT Press, 1999.

DESGRANGES, Flávio. A pedagogia do espectador. Tese ( Doutorado). São Paulo: Universidade de São Paulo/ Faculdade de Educação, 2001.

. Teatralidade tátil: alterações no ato do espectador. Revista Sala Preta, São Paulo,V.1, n. 8, p. 11-20, 2008.

A inversão da olhadela: no rastro da refuncionalização da arte teatral. Tese (Livre Docência). São Paulo: Universidade de São Paulo/Escola de Comunicações e Artes, 2009.

DEWEY, John. Arte como experiência. São Paulo: Martins Fontes, 2010.

FAVERO, Ana Beatriz. A noção de trauma em psicanálise. Tese (Doutorado). Rio de Janeiro: Pontifícia Universidade Católica, 2009.

FÉRAL, Josette. O real na arte: a estética do choque. Transcrição da palestra proferida no VI Congresso da Associação Brasileira de Pesquisa e Pós-Graduação em Artes Cênicas, nov. 2010. 
. Por uma poética da performatividade: o teatro performativo. Revista Sala Preta, São Paulo, V.1, No 8, p. 197-210, 2008.

. Theatricality: the specificity of theatrical language. Substance 98/99, vol. 31, n. 2 e 3, p. 94-108, 2002

FERNANDES, Silvia. Teatralidades contemporâneas. São Paulo: Perspectiva, 2010.

FREUD, Sigmund. O mal estar na civilização, novas conferências introdutórias à psicanálise e outros textos - tradução Paulo César de Souza. São Paulo: Cia. das Letras, 2010.

. Escritos sobre a psicologia do inconsciente. V.II. Rio de Janeiro: Imago, 2006.

GUINSBURG, J. \& FERNANDES, Silvia (orgs). O pós-dramático: um conceito operativo?. São Paulo: Perspectiva, 2008.

HELENE, André F. \& XAVIER, Gilberto F. A construção da atenção a partir da memória. Revista Brasileira de Psiquiatria, São Paulo, n. 25, supl. 2, p. 12-20, 2003.

KIHLSTROM, John F. The cognitive unconscious. Science, Nova Iorque, v. 237, p. 1445-1452, 1987.

KRACAUER, Siegfried. O ornamento da massa. São Paulo: Cosac Naify, 2009.

LEHMANN, Hans-Thies. Teatro pós-dramático. São Paulo: Cosac\&Naify, 2007a.

. Motivos para desejar uma arte da não-compreensão. Revista Urdimento, Florianópolis, V.1, N. 9, p.141-152, 2007b.

MUNSTERBERG, Hugo. The Film: A Psychological Study. New York: Dover Publications, 2004.

NAHAS, T. R.; XAVIER G. F. Atenção. In: BUENO, Andrade Santos. Neuropsicologia Hoje. São Paulo: Artes Médicas, 2004.

PAVIS, Patrice. A análise dos espetáculos. São Paulo: Perspectiva, 2003.

2010.

A encenação contemporânea: origens, tendências, perspectivas. São Paulo: Perspectiva,

RANCIÈRE, Jacques. O espectador emancipado. Revista Urdimento, Florianópolis, v. 1, n. 15, p. 107-122, 2010a.

O Mestre Ignorante: cinco lições sobre a emancipação intelectual. Belo Horizonte: Autentica, 2010b.

SARRAZAC, Jean-Pierre. A invenção da teatralidade. Lisboa: Deriva Editores, 2009.

\footnotetext{
1 Este artigo é uma revisão que retoma e sintetiza alguns resultados da dissertação de mestrado "A atenção e a cena", defendida em 2011 com bolsa CAPES, sob orientação do prof. Dr. Luiz Fernando Ramos no Programa de Pós-Graduação em Artes Cênicas da USP.
}

2 A cena contemporânea, a qual nos referimos, é composta por encenações que tem algumas características em comum, apesar de não constituírem uma linguagem homogênea. Dentre estas características podemos citar a explosão da narrativa, a utilização intensa 
de composições imagéticas e a produção de significados opacos e indiretos. Dentre alguns exemplos podemos citar os espetáculos encenados pela Socìetas Raffaello Sanzio, Teatro da Vertigem, Cia dos Atores, Lola Arias, Rimini Protokoll, entre outros.

3 Atualmente as reflexões aqui introduzidas estão sendo utilizadas como base da pesquisa de doutoramento desenvolvida junto à Universidade de São Paulo, fomentada pela Fundação de Amparo da Pesquisa do Estado de São Paulo, sob o título "Experiência e Teatralidade",

4 Utiliza-se o termo teatralidade nesta pesquisa a partir da abordagem de Fernandes (2010, p.113) por se entender que "o conceito de teatralidade tem se revelado um instrumento eficaz de operação do teatro contemporâneo, especialmente por levar em conta a proliferação de discursos de caráter eminentemente cênico que manejam, em sua produção, e em diferentes graus, múltiplos enunciadores do discurso teatral"

5 Estamos desenvolvendo atualmente, dentro do projeto de doutoramento, uma pesquisa sobre projetos de formação de público brasileiros, pensando em como este tipo de abordagem pode influenciar o olhar do espectador e sobre a aplicabilidade deste tipo de formação tendo em vista a linguagem das teatralidades contemporâneas. 